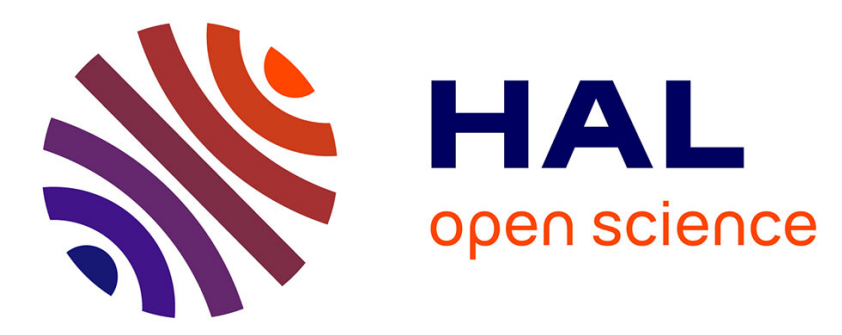

\title{
Metabolic analysis of elicited cell suspension cultures of L. by H-NMR spectroscopy
}

\author{
Jaroslav Peč, Isvett Josefina Flores-Sanchez, Young Hae Choi, Robert \\ Verpoorte
}

\section{- To cite this version: \\ Jaroslav Peč, Isvett Josefina Flores-Sanchez, Young Hae Choi, Robert Verpoorte. Metabolic analysis of elicited cell suspension cultures of L. by H-NMR spectroscopy. Biotechnology Letters, 2010, 32 (7), pp.935-941. 10.1007/s10529-010-0225-9 . hal-00576175}

\section{HAL Id: hal-00576175 \\ https://hal.science/hal-00576175}

Submitted on 13 Mar 2011

HAL is a multi-disciplinary open access archive for the deposit and dissemination of scientific research documents, whether they are published or not. The documents may come from teaching and research institutions in France or abroad, or from public or private research centers.
L'archive ouverte pluridisciplinaire HAL, est destinée au dépôt et à la diffusion de documents scientifiques de niveau recherche, publiés ou non, émanant des établissements d'enseignement et de recherche français ou étrangers, des laboratoires publics ou privés. 


\title{
Metabolic analysis of elicited cell suspension cultures of Cannabis sativa L. by ${ }^{1} \mathrm{H}-\mathrm{NMR}$ spectroscopy
}

\author{
Jaroslav Peč • Isvett Josefina Flores-Sanchez • \\ Young Hae Choi $\cdot$ Robert Verpoorte
}

Received: 5 January 2010/Accepted: 17 February 2010/Published online: 13 March 2010

(C) Springer Science+Business Media B.V. 2010

\begin{abstract}
Cannabis sativa L. plants produce a diverse array of secondary metabolites. Cannabis cell cultures were treated with jasmonic acid (JA) and pectin as elicitors to evaluate their effect on metabolism from two cell lines using NMR spectroscopy and multivariate data analysis. According to principal component analysis (PCA) and partial least squarediscriminant analysis (PLS-DA), the chloroform extract of the pectin-treated cultures were more different than control and JA-treated cultures; but in the methanol/ water extract the metabolome of the JA-treated cells showed clear differences with control and pectin-treated cultures. Tyrosol, an antioxidant metabolite, was detected in cannabis cell cultures. The tyrosol content increased after eliciting with JA.
\end{abstract}

Electronic supplementary material The online version of this article (doi:10.1007/s10529-010-0225-9) contains supplementary material, which is available to authorized users.

I. J. Flores-Sanchez · Y. H. Choi · R. Verpoorte $(\bowtie)$ Section of Metabolomics, Pharmacognosy Department, Institute of Biology, Gorlaeus Laboratories,

Leiden University, P.O. Box 9502,

2300 RA Leiden, The Netherlands

e-mail: verpoort@chem.leidenuniv.nl

I. J. Flores-Sanchez

e-mail: i.flores.sanchez@chem.leidenuniv.nl

J. Peč

Faculty of Pharmacy, Pharmacognosy Department,

Charles University in Prague, Heyrovského 1203,

50005 Hradec Králové, Czech Republic
Keywords Cannabis sativa $\cdot$ Cell suspension cultures - Elicitation - Metabolomics .

Nuclear magnetic resonance spectroscopy ·

Tyrosol

\section{Introduction}

Cannabis sativa $\mathrm{L}$. is an annual dioecious plant from Central Asia. A number of secondary metabolites have been described to occur in this plant (FloresSanchez and Verpoorte 2008). Cannabinoids are a well known group of natural products in this plant and more than 70 different cannabinoids have been found so far (ElSohly and Slade 2005). Several therapeutic effects of cannabinoids have been described (Williamson and Evans 2000) and the discovery of the endocannabinoid system in mammals marked a renewed interest in these compounds (Heifets and Castillo 2009).

Metabolomics is a rapidly developing discipline in plant biology and has become an integral part of many functional genomics programs (Hagel and Facchini 2008). In recent years metabolite profiling has become routinely applicable across biology, being useful for phenotyping and diagnostic analyses. Several analytical platforms have been proposed for characterizing and quantifying the metabolites in plants in a systematic manner (Hagel and Facchini 2008). ${ }^{1} \mathrm{H}-\mathrm{NMR}$ spectroscopy is one of these platforms which is currently being explored together with 
principal component analysis (PCA) and partial least square-discriminant analysis (PLS-DA), the most common methods to analyze the variability in a group of samples.

Metabolic pathway fluxes depend on the environment in which the cell is grown. For example, in plant cell cultures and plants treated with biotic elicitors clear qualitative and quantitative variations in the metabolic pool were shown (Sanchez-Sampedro et al. 2007; Jahangir et al. 2008). Although, cannabis cell cultures do not produce cannabinoids, even after elicitation treatments (Flores-Sanchez et al. 2009), analyses in the content of the metabolite pool from two cell lines were made in order to study the effect of elicitation on the Cannabis sativa cell suspension culture metabolome. Here, we report the results from these studies.

\section{Materials and methods}

\section{Chemicals}

Chloroform- $d(99.80 \%, \mathrm{v} / \mathrm{v})$ and methanol- $d_{4}(99.80 \%$, $\mathrm{v} / \mathrm{v})$ were obtained from Euriso-top (Paris, France). Water- $d_{2}(99 \%, v / v)$ was acquired from Spectra Stable Isotopes (Columbia, MD, USA). $\mathrm{NaOH}-d$ was purchased from Cortec (Paris, France). All chemical products and mineral salts were of analytical grade.

Plant material and cell culture methods

Cell suspension cultures were induced from leaf explants of Cannabis sativa L. (drug type variety Fourway) and were maintained in MS basal medium (Murashige and Skoog 1962) supplied with B5 vitamins (Gamborg et al. 1968), $2 \mathrm{mg}$ 2,4-D/1, $1 \mathrm{mg}$ kinetin $/ 1$ and 30 sucrose $\mathrm{g} / \mathrm{l}$. Cells were subcultured with a 3-fold dilution every 2 weeks. Cultures were grown at $25^{\circ} \mathrm{C}$ with shaking at $110 \mathrm{rpm}$ and under a light intensity of $14-23.8 \mu \mathrm{mol} / \mathrm{m}^{2} \mathrm{~s}$. Cellular viability measurement was according to Widholm (1972).

\section{Elicitation}

Jasmonic acid (JA, Sigma) was dissolved in $30 \%$ (v/v) ethanol. Pectin suspensions from Citrus fruits (87\% galacturonic acid and $8.7 \%$ methoxy groups,
Sigma) were prepared according to the method of Flores-Sanchez et al. (2002).

Erlenmeyer flasks $(250 \mathrm{ml})$ containing $50 \mathrm{ml}$ medium were inoculated with $5 \mathrm{~g}$ fresh cells. Five days after inoculation $100 \mu \mathrm{M}$ JA or $50 \mathrm{mg}$ pectin was added to the suspension. The cultures were harvested every 2 days.

Extraction of compounds for the metabolic profiling

Metabolite extraction was carried out as described by Choi et al. (2004) with slight modifications. To $0.1 \mathrm{~g}$ of lyophilized plant material either $4 \mathrm{ml}$ methanol/ water $(1: 1, \mathrm{v} / \mathrm{v})$ or $4 \mathrm{ml}$ chloroform was added, mixed for $30 \mathrm{~s}$ and sonicated for $10 \mathrm{~min}$. The mixtures were centrifuged at $4^{\circ} \mathrm{C}$ and $1200 \times g$ for $20 \mathrm{~min}$. Each extraction was performed twice. The methanol/water and chloroform fractions were separated and evaporated. Extractions with ethyl acetate were also performed. The organic phase was dried over anhydrous $\mathrm{Na}_{2} \mathrm{SO}_{4}$ and evaporated. Extracts were stored at $4^{\circ} \mathrm{C}$.

NMR measurements and data analyses

The dried fractions were dissolved in chloroform- $d$ and methanol- $d_{4}$ : water- $d_{2}(1: 1, \mathrm{v} / \mathrm{v}, \mathrm{pH} 6)$, respectively. $\mathrm{KH}_{2} \mathrm{PO}_{4}$ was used as a buffering agent for methanol- $d_{4}$ : water- $d_{2}$. Sodium trimethylsilyl propionate (TMSP) was used as internal standard for methanol- $d_{4} /$ water- $d_{2}$. Dried medium extracts were dissolved in methanol- $d_{4}$. Measurements were carried out at $25^{\circ} \mathrm{C}$ using a Bruker AV-500 NMR instrument operating at a proton NMR frequency of $500.13 \mathrm{MHz}$. For each sample, 128 scans were recorded using the same parameters as previously reported by Choi et al. (2004). The ${ }^{1} \mathrm{H}-\mathrm{NMR}$ spectra were automatically reduced to ASCII files using AMIX (v. 3.7, Bruker Biospin). Spectral intensities were scaled to total intensity for the chloroform and methanol extracts and to TMSP for the methanol/water extract and reduced to integrated regions of equal width $(0.04 \mathrm{ppm})$ corresponding to the region $\delta 0.3-10$. The regions of $\delta$ 3.30-3.34, $\delta$ 4.74-4.98 and $\delta$ 7.18-7.3 were excluded from the analyses because of the residual signal of methanol, water and chloroform, respectively. Principal component analysis (PCA) and partial least square-discriminant analysis (PLS-DA) 
were performed with the SIMCA-P software (v. 11.0, Umetrics Umeå, Sweden). Compounds were quantified by the relative ratio of the intensities of their peak-integrals and the ones of internal standard according to Flores-Sanchez et al. (2009). The characteristic ${ }^{1} \mathrm{H}$-chemical shifts $(\delta)$ and coupling constant $(\mathrm{Hz})$ of identified metabolites were previously reported (Flores-Sanchez et al. 2009). For structure elucidation of aromatic metabolites, ${ }^{1} \mathrm{H}-\mathrm{NMR}$ and 2D-NMR (HMBC, HMQC, J-Resolved and ${ }^{1} \mathrm{H}-{ }^{1} \mathrm{H}-\mathrm{COSY}$ ) was used as described by Choi et al. (2004) and for aromatic compound isolation Sephadex LH20 column chromatography with methanol as eluent was used. Eighteen fractions were collected and the profiles were analyzed by TLC with silica gel $60 \mathrm{~F}_{254}$ plates, developed in methanol/ chloroform $(9: 1, \mathrm{v} / \mathrm{v})$ and revealed with anisaldehyde/sulfuric acid reagent. Fractions 4 and 5 were mixed and purified by solid phase extraction (SPE) using SEP-Pak Cartridge Plus C18 (Waters, Milford, MA, USA). From the first elution using water, phenylalanine together with traces of tyrosine and tyramine were identified. From the second elution using methanol/water $(1: 1, \mathrm{v} / \mathrm{v})$, tyrosine, tyrosol, tyramine and tyramine glycoside were identified (Fig. 7).

\section{Statistics}

Data were analyzed by MultiExperiment Viewer MEV 4.0 software (TM4 Software Suite, J. Craig Venter Institute, Rockville, MD, USA). For analyses involving two and three or more groups paired $t$-test, ANOVA, PCA and PLS-DA were used, respectively with $\alpha=0.05$ for significance. Values are expressed as means of three replicates with standard deviations.

\section{Results and discussion}

Two cell lines were generated from leaf explants which were either green (GC cells) or greenish brown (GB cells). According to the principal component analysis (PCA) from the chloroform fraction, the two cell lines were separated by cell line type (second principal component, PCA2) and developmental stage (first principal component, PCA1) (Fig. 1a). The loading plot suggests that in the younger samples unsaturated fatty acids are predominant; while in
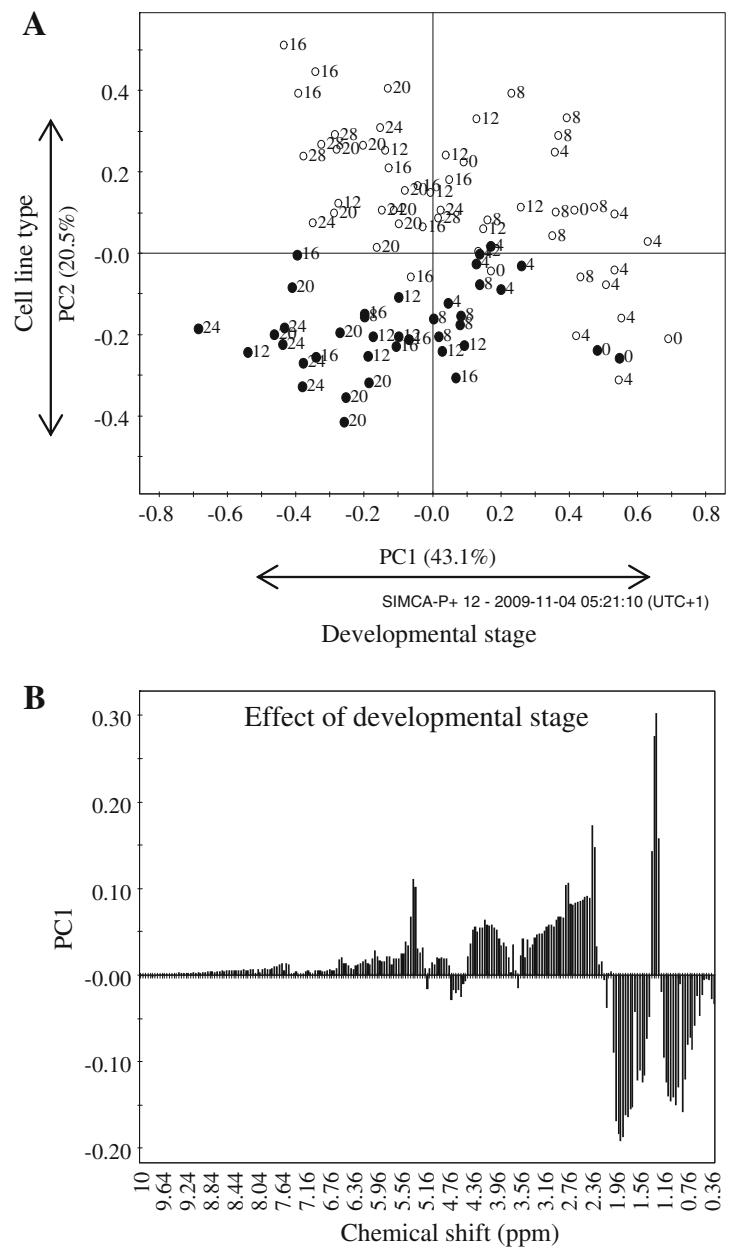

SIMCA-P+ 12 - 2009-11-04 05:27:00 (UTC+1)

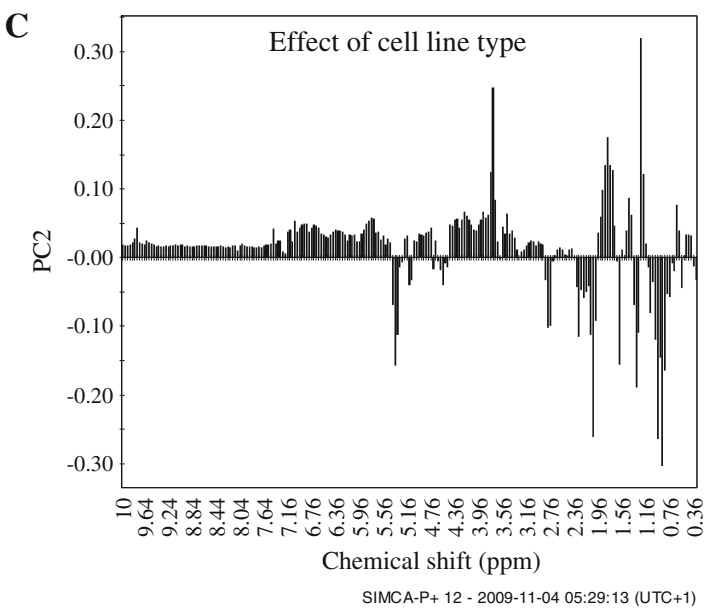

Fig. 1 Principal component analysis (PCA) from ${ }^{1} \mathrm{H}-\mathrm{NMR}$ data of $\mathrm{CHCl}_{3}$ fractions from the control cell lines green (GC, open circle) and greenish-brown (GB, filled circle). a Score plot, b PC1 loading plot, c PC2 loading plot. Numbering represents developmental stage or culture age (from day 0-28) 

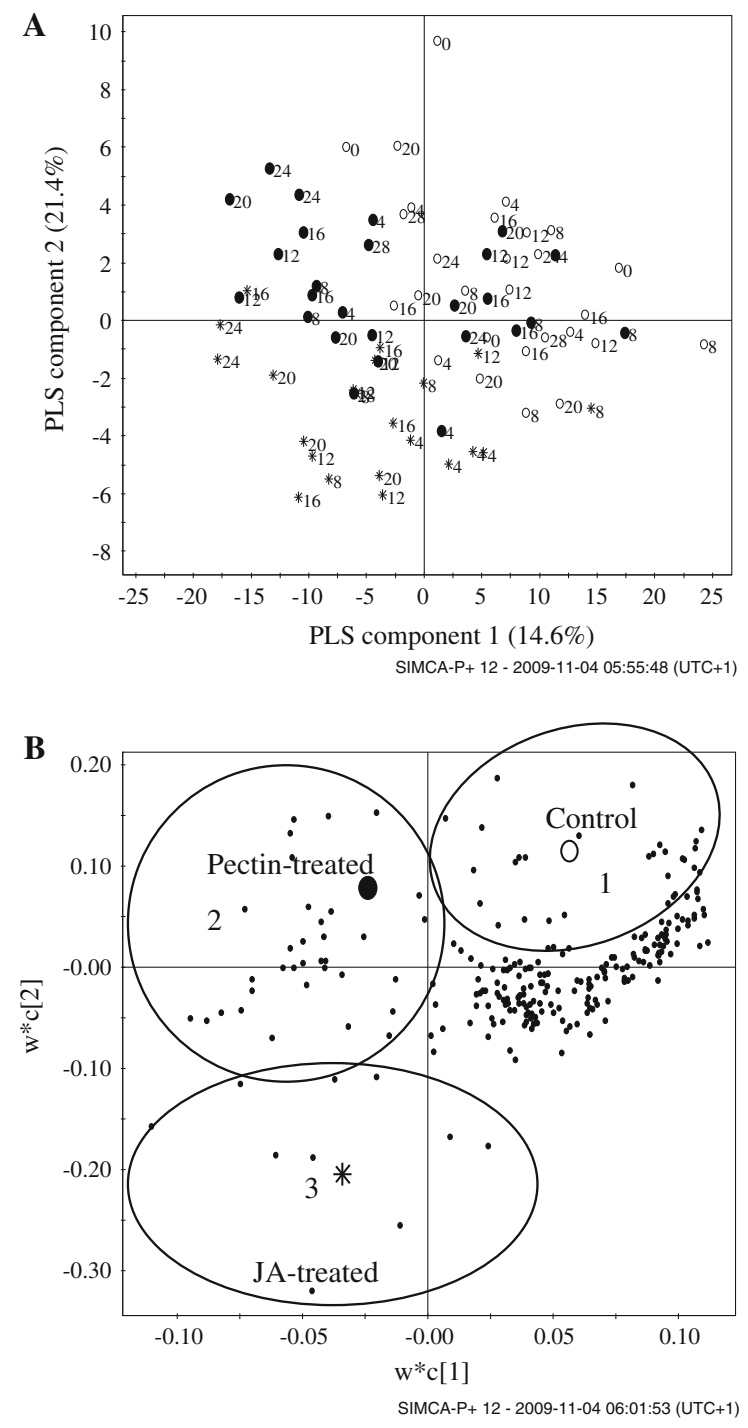

Fig. 2 Score (a) and loading (b) plots of PLS-DA analysis from ${ }^{1} \mathrm{H}-\mathrm{NMR}$ data of chloroform fractions. open circle control, asterisk JA-treated, filled circle Pectin-treated. a Numbering represents developmental stage or culture age (from day 0-28). b Control region in loading plot contains unsaturated fatty acids (1); pectin-treated region contains saturated fatty acids (2) and JA-treated region contains unsaturated fatty acids (3)

older samples saturated fatty acids are predominant (Fig. 1b). The ${ }^{1} \mathrm{H}-\mathrm{NMR}$ spectral region of 5.08$5.4 \mathrm{ppm}(\delta)$ represents signals of double bonds from unsaturated fatty acids and the region of $\delta 0.8-1.9$ represents signals from saturated fatty acids. Both cell lines have a different profile of saturated fatty acids and unsaturated fatty acids could be a marker for the
Fig. 3 Score (a), PC1 loading (b) and PC4 loading (c) plots of PCA analysis from ${ }^{1} \mathrm{H}-\mathrm{NMR}$ data of methanol-water fractions from the cell lines green (GC, open circle) and greenish-brown (GB, filled circle). Numbering is developmental stage or culture age (from day 0-28)

cell line GB as they are the predominant fatty acids in this cell line (Fig. 1c).

Both cell lines were elicited with JA and pectin. According to partial least square-discriminant analysis (PLS-DA) from the chloroform fraction the pectin treatment had more effect on the metabolism of saturated fatty acids in both cell lines than the JA treatment (Fig. 2). The separation between control and JA-treated cultures is due to a difference in the unsaturated fatty acid contents. No cannabinoid signals were detected, as it was reported previously (FloresSanchez et al. 2009).

When the methanol/water fraction from control samples was analyzed, a separation was found between the two cell lines based on cell line type (PC4) and developmental stage or culture age (PCA1) (Fig. 3). According to the loading plot of PC1 (Fig. 3b), aromatic compounds tend to predominate in older cultures. Based on PC4, in GB cultures alanine $(\delta$ 1.48), GABA ( $\gamma$-aminobutyric acid, $\delta 1.90, \delta 2.31$ and $\delta$ 3.0) and sucrose ( $\delta$ 5.4) were dominant metabolites. In GC cultures leucine $(\delta 1.71)$, glutamine $(\delta 2.13)$, glutamic acid $(\delta 2.45)$, aspartic acid $(\delta 3.95)$, tryptophan $(\delta$ 7.72) and tyrosine $(\delta 3.86)$ were the dominant metabolites (Fig. 3c). The methanol/water fractions from elicited samples show a different metabolic profiling compared to the control samples (Fig. 4). JA elicitation had a stronger effect on the metabolome of both cell lines than pectin elicitation. Based on PLS-DA analysis sucrose, glucose, choline, valine, isoleucine, glutamic acid and GABA were the predominant metabolites in pectin-treated cultures from both cell lines (Fig. 4b).

Phenylalanine, tyrosine, tyrosol, tyramine and tyramine glucoside (Fig. 7) were the aromatic compounds identified in the aromatic region $(\delta 6.0-8.0)$ of the NMR spectra of JA-treated cultures (Supplementary Table 1; Fig. 4b). Induction of phenylalanine, tyramine and tyrosine in $C$. sativa cell suspension cultures by JA elicitation has been reported (FloresSanchez et al. 2009). A time-course shows that the elicitation with JA increased the tyrosol concentration twofold in GB cell cultures if compared to GC cell cultures at day 16 (Fig. 5). The content of tyrosol from 

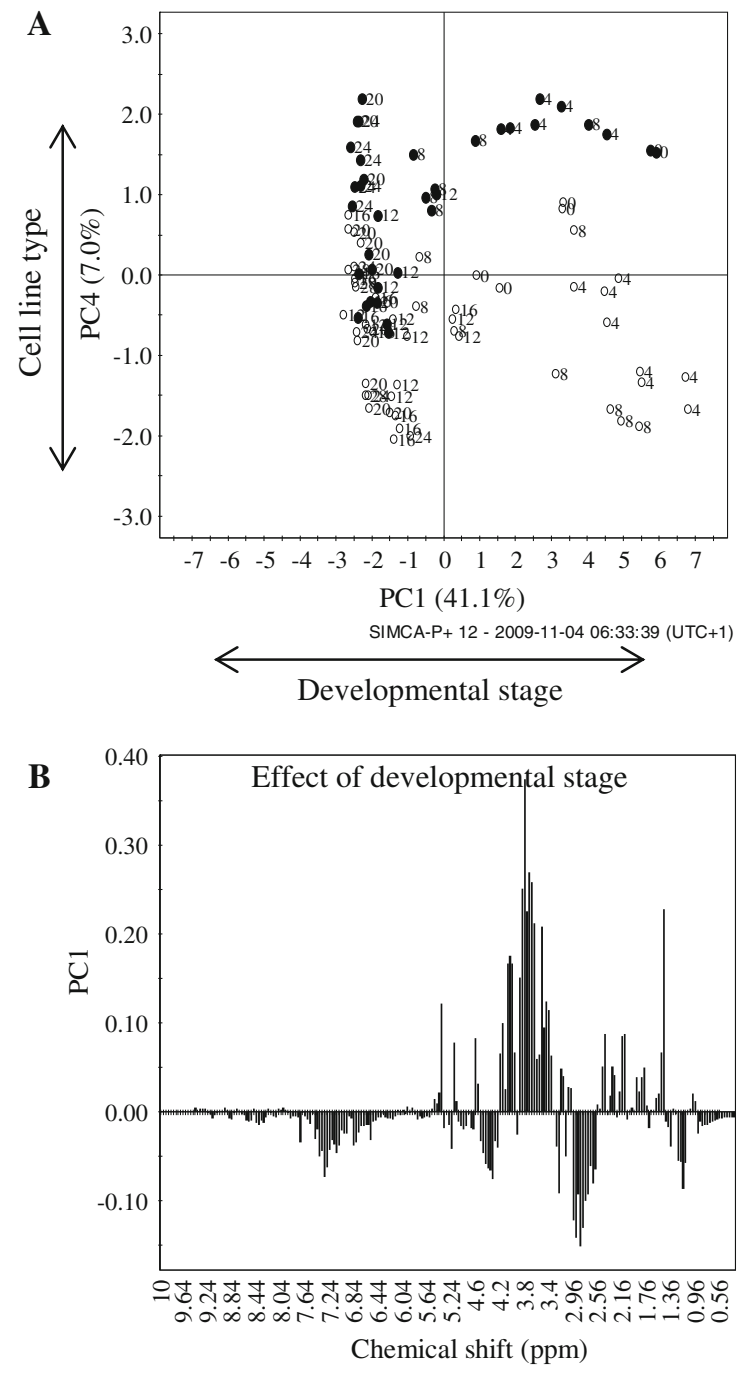

SIMCA-P+ 12 - 2009-11-04 06:52:08 (UTC+1)

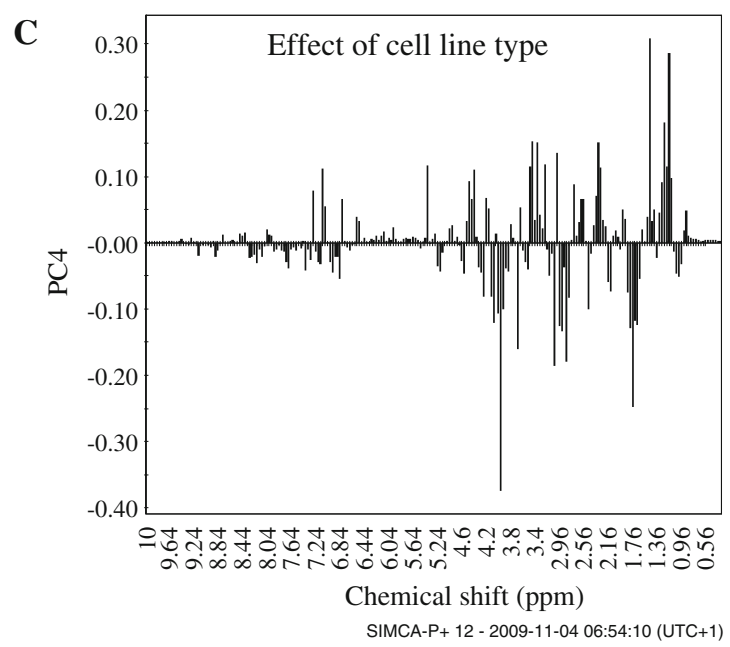

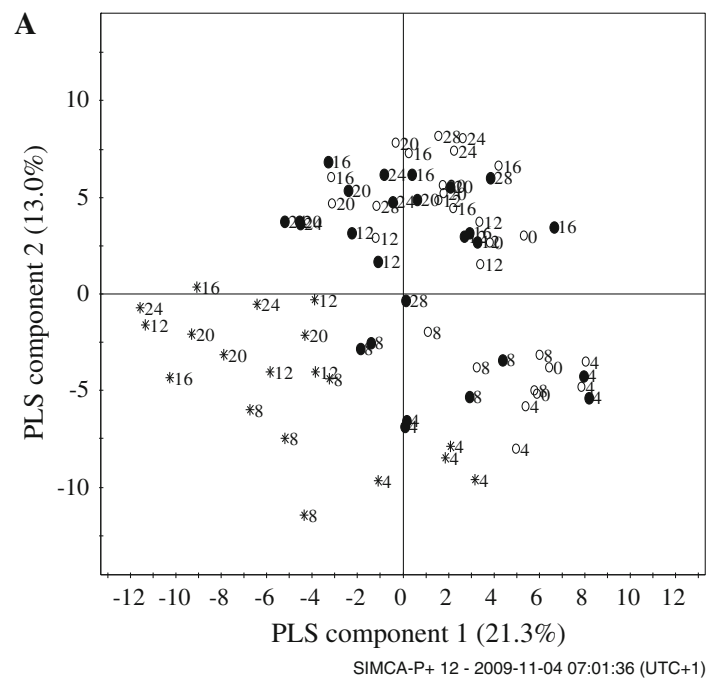

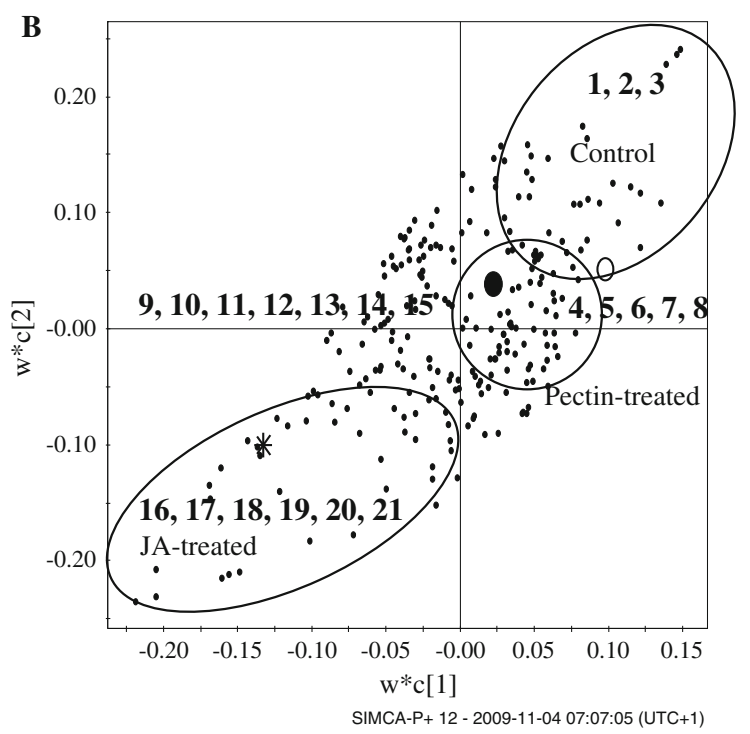

Fig. 4 Score (a) and loading (b) plots of PLS-DA analysis from ${ }^{1} \mathrm{H}-\mathrm{NMR}$ data of methanol-water fractions. Open circle control, asterisk JA-treated, filled circle pectin-treated. a Numbering is developmental stage or culture age (from day 0-28). b Control region in loading plot contains leucine (1), aspartic acid (2), tryptophan (3), trigonelline (4), glutamine (5), threonine (6), adenosine (7) and cytidine (8); pectin-treated region contains sucrose (9), glucose (10), choline (11), valine (12), isoleucine (13), $\gamma$-amino-butyric acid (GABA, 14) and glutamic acid (15); and JA-treated region contains phenylalanine (16), tyrosine (17), tyramine (18), tyramine glycoside (19), tyrosol (20) and ethanol glucoside (21)

both cell lines was not significantly affected by elicitation with pectin $(n=3$ per group, Anova, $P<0.05)$. Tyrosol is one of the main phenolic 


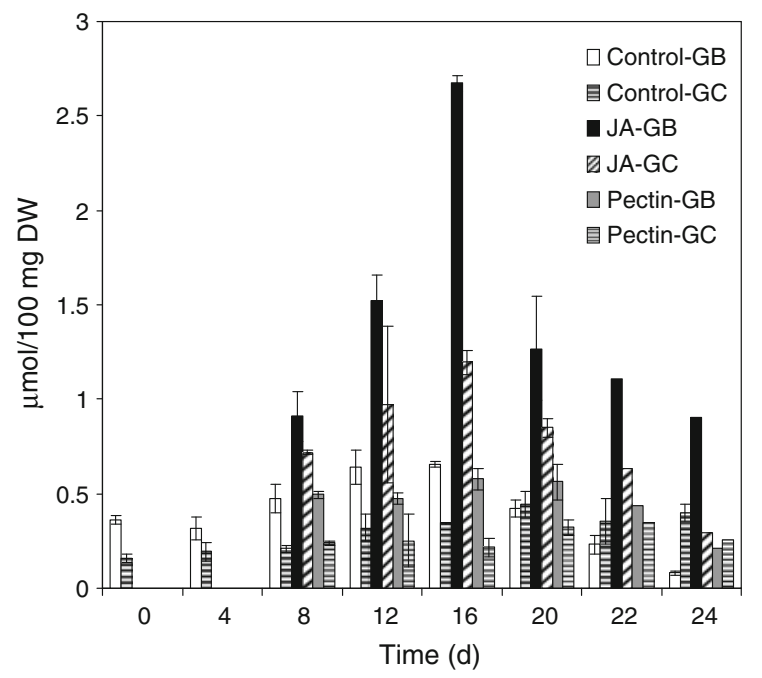

Fig. 5 Time course of tyrosol content in the control, $J A$ and pectin-treated cannabis cell cultures. $G C$ green cell line, $G B$ greenish-brown cell line

compounds present in olive oil (Aturki et al. 2008; Sotiroudis and Kyrtopoulos 2008). It has an antioxidant activity (Giovannini et al. 1999). Tyrosol occurs in plants of the Rhodiola species (Li and Zhang 2008) and in foliar fungal endophytes of Picea glauca (Sumarah et al. 2008). There are no previous reports about the presence of tyrosol in C. sativa. Analysis of the tyrosol content by ${ }^{1} \mathrm{H}-\mathrm{NMR}$ spectroscopy between virgin olive oil $(0.06 \mu \mathrm{mol} / 100 \mathrm{mg}$; Christophoridou and Dais 2009) and the elicited cannabis cell lines $(2.7 \pm 0.1 \mu \mathrm{mol} / 100 \mathrm{mg}$ in GB line and $1.2 \pm$ $0.01 \mu \mathrm{mol} / 100 \mathrm{mg}$ in GC line) suggests that cannabis cell suspension culture could be used for the production of this antioxidant metabolite.

Principal component analysis (PCA) analysis of the methanol fraction from medium extracts of the control and elicited cell cultures shows that the cell line GC secretes tyrosine, tyrosol and tyramine into the culture medium (Figs. 6, 7; Supplementary Table 2). Apparently, the excretion of these aromatic compounds was not affected by JA or pectin treatment in the GC cell line and it could be an inherent part of the metabolism of this cell line.

Fig. 6 Loading column plots of PCA analysis from ${ }^{1} \mathrm{H}-\mathrm{NMR}$ data of methanol fractions from medium extracts. a Control, b JA-treated and c pectin-treated cell suspension cultures. Signals that correspond to the aromatic region of ${ }^{1} \mathrm{H}-\mathrm{NMR}$ spectra are in dashed circles. $G C$ green, $G B$ greenish-brown
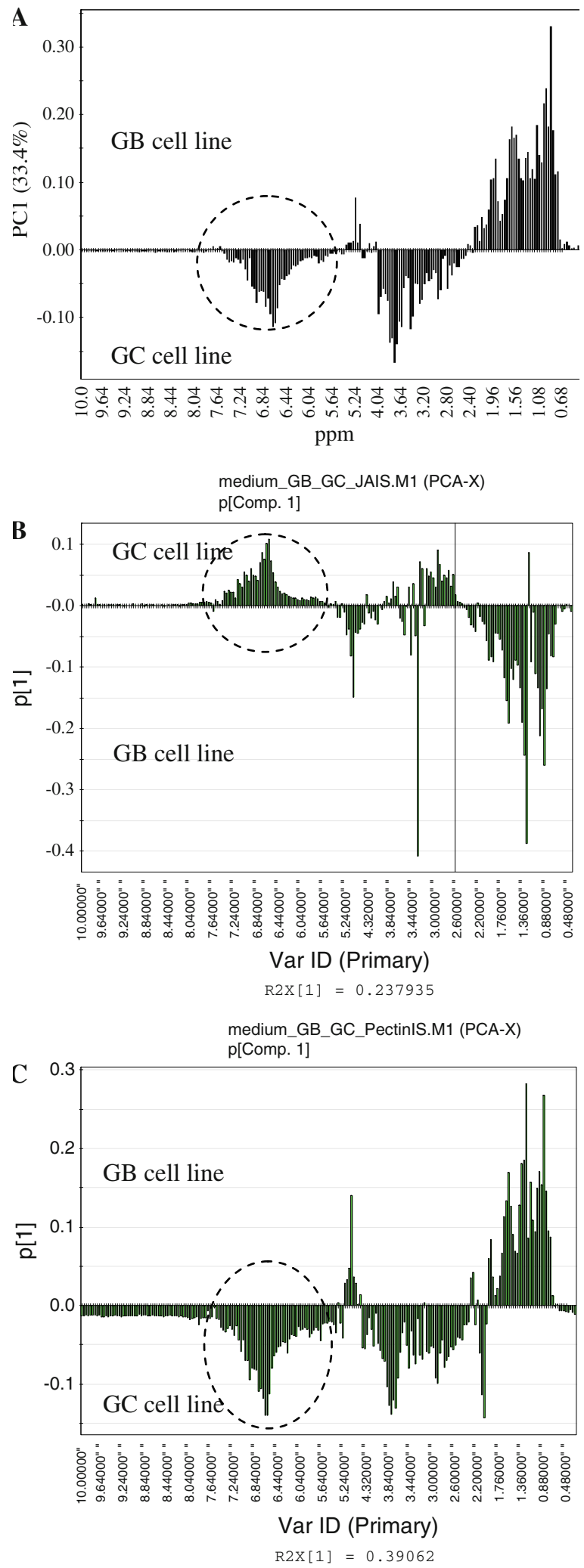

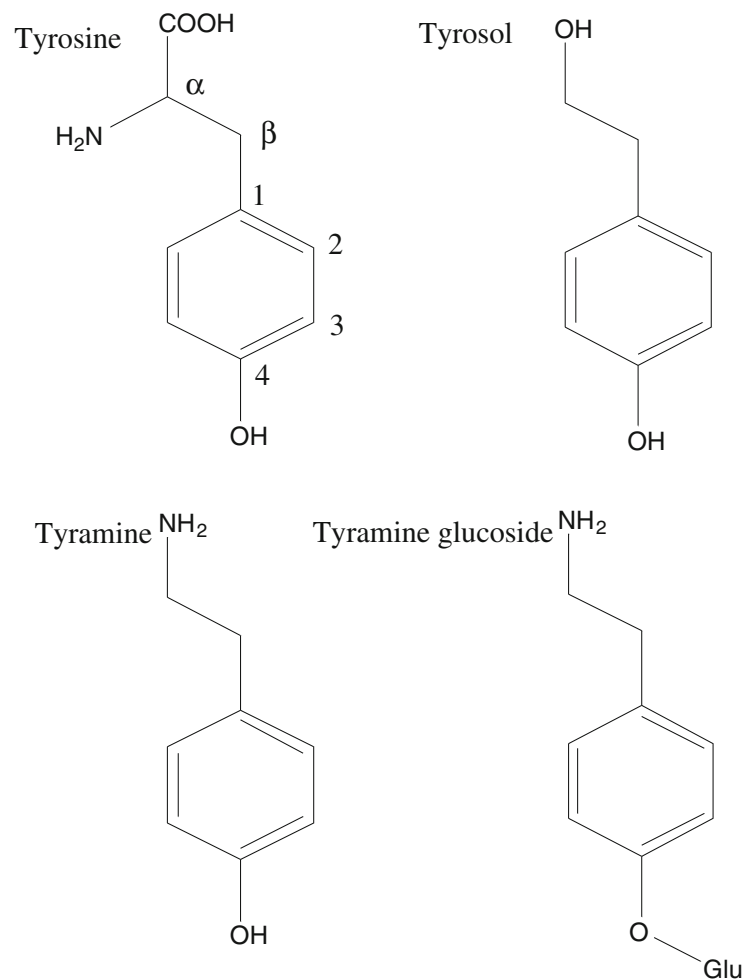

Fig. 7 Structures of tyrosine and its metabolites identified from methanol/water and methanol fractions

In this study, we identified metabolites (Fig. 7) that differentiate the two cannabis cell lines from each other and indicate how these cell lines respond to the effect of elicitation by JA and pectin.

Acknowledgements I.J. Flores Sanchez received a partial grant from Consejo Nacional de Ciencia y Tecnologia (Mexico) and J. Peč received a grant from Ministry of Education of the Czech Republic (MSM 0021620822).

\section{References}

Aturki Z, Fanali S, D’Orazio G et al (2008) Analysis of phenolic compounds in extra virgin olive oil by using reversed-phase capillary electrochromatography. Electrophoresis 29:1643

Choi YH, Kim HK, Hazekamp A et al (2004) Metabolomic differentiation of Cannabis sativa cultivars using ${ }^{1} \mathrm{H}-\mathrm{NMR}$ spectroscopy and principal component analyses. J Nat Prod 67:953-957

Christophoridou S, Dais P (2009) Detection and quantification of phenolic compounds in olive oil by high resolution ${ }^{1} \mathrm{H}$-nuclear magnetic resonance spectroscopy. Anal Chim Acta 633:283-292

ElSohly MA, Slade D (2005) Chemical constituents of marijuana: the complex mixture of natural cannabinoids. Life Sci 78:539-548

Flores-Sanchez IJ, Verpoorte R (2008) Secondary metabolism in cannabis. Phytochem Rev 7:615-639

Flores-Sanchez IJ, Ortega-Lopez J, Montes-Horcasitas MC et al (2002) Biosynthesis of sterols and triterpenes in cell suspension cultures of Uncaria tomentosa. Plant Cell Physiol 43:1502-1509

Flores-Sanchez IJ, Peč J, Fei J et al (2009) Elicitation studies in cell suspension cultures of Cannabis sativa L. J Biotechnol 143:157-168

Gamborg OL, Miller RA, Ojima K (1968) Nutrient requirements of suspension cultures of soybean root cells. Exp Cell Res 50:151-158

Giovannini C, Straface E, Modesti D et al (1999) Tyrosol, the major olive oil biophenol, protects against oxidized-LDLindiced injury in Caco-2 cell. J Nutr 129:1269-1277

Hagel JM, Facchini PJ (2008) Plant metabolomics: analytical platforms and integration with functional genomics. Phytochem Rev 7:479-497

Heifets BD, Castillo PE (2009) Endocannabinoid signaling and long-term synaptic plasticity. Annu Rev Physiol 71: 283-306

Jahangir M, Kim HK, Choi YH et al (2008) Metabolomic response of Brassica rapa submitted to pre-harvest bacterial contamination. Food Chem 107:362-368

Li T, Zhang H (2008) Identification and comparative determination of rhodionin in traditional Tibetan medicinal plants of fourteen Rhodiola species by high-performance liquid chromatography-photodiode array detection and electrospray ionization-mass spectrometry. Chem Pharm Bull 56:807-814

Murashige T, Skoog F (1962) A revised medium for rapid growth and bioassays with tobacco cultures. Physiol Plant 15:473-497

Sanchez-Sampedro A, Kim HK, Choi YH et al (2007) Metabolomic alterations in elicitor treated Silybum marianum suspension cultures monitored by nuclear magnetic resonance spectroscopy. J Biotechnol 13:133-142

Sumarah MW, Puniani E, Blackwell BA et al (2008) Characterization of polyketide metabolites from foliar endophytes of Picea glauca. J Nat Prod 71:1393-1398

Widholm JM (1972) The use of fluorescein diacetate and phenosafranine for determining viability of cultured plant cells. Stain Technol 47:189-194

Williamson EM, Evans FJ (2000) Cannabinoids in clinical practice. Drugs 60:1303-1314 